\title{
A Formação Continuada dos Tutores do Curso de Pedagogia a Distância no modelo de Comunidades de Aprendizagem.*
}

\author{
Mariangela Lenz Ziede ${ }^{1}$ \\ Rosane Aragón de Nevado ${ }^{2}$ \\ ${ }^{1,2}$ Programa de Pós-Graduação em Educação, Faculdade de Educação, \\ ${ }^{1,2}$ Universidade Federal do Rio Grande do Sul (UFRGS), Porto Alegre - RS - Brasil \\ mariangela.ziede@ufrgs.br, rosane.aragon@ufrgs.br
}

Resumo. O presente artigo apresenta os fundamentos, a organização e algumas práticas desenvolvidas na formação continuada dos tutores do Curso de Graduação em Pedagogia na modalidade a distância da UFRGS (PEAD). O Curso teve início em 2006, sendo oferecido a professores em exercício em escolas públicas de Educação Infantil e Anos Iniciais do Ensino Fundamental. A formação dos tutores e sua atuação junto aos alunos acompanham a proposta do Curso, de base interacionista e construtivista, apoiada no uso intensivo de tecnologias digitais. A análise das atividades dos tutores, até o presente momento, tem apontado para um movimento de compreensão gradual dos fundamentos teóricos e práticas educacionais do Curso, bem como as necessidades de aprofundamento da formação na perspectiva da construção do papel do tutor e o fortalecimento da comunidade de aprendizagem.

Palavras chaves: Educação a distância; comunidades de aprendizagem; formação continuada dos tutores.

\section{The Continuing Education of the tutors of the Distance Education Course on the model of Learning Communities.}

Abstract: This paper aims to present the fundamentals, the organization and some practices developed in the training of tutors in the distance of Pedagogy Degree of UFRGS (PEAD). The course began in 2006, focused in public schools teachers and elementary school teachers. The training of tutors, in the learning communities model, and their actions with the student, are developing and supporting by integrationists and constructivists bases, and digital technologies. The analysis of tutor's activities, so far, show us a gradual movement of understanding of the theoretical reasons and educational practices of course, as well as the need for extensive training in the preparation for the construction of the role of tutor and the strengthening of the learning's communities.

\footnotetext{
* Uma versão preliminar deste artigo foi apresentada parcialmente em formato de pôster no ESUD 2008 V Congresso Brasileiro de Ensino Superior a Distância e $6^{\circ}$ SENAED Seminário Nacional de Educação a Distância em Gramado.

V. 6 № 1, Julho, 2008
} 
Keywords: Long distance learning; communities of learning; continued training of tutors.

\section{Introdução}

A formação do professor é um processo continuado que alia a prática docente ao aperfeiçoamento constante por via de diferentes modalidades de estudo e reflexão. As inúmeras iniciativas atualmente desenvolvidas pelas Universidades Públicas do país constituem uma clara demonstração de que tais instituições estão traduzindo concretamente o compromisso de contribuir para a formação continuada dos professores brasileiros.

Na região Sul, ainda que a situação seja distinta de regiões como o Norte e o Nordeste do país quanto à titulação em nível superior de professores que atuam nos anos iniciais do ensino fundamental, há carências a serem supridas. Em resposta a essa demanda e apoiada pelo conhecimento adquirido na área de Educação a Distância, a Faculdade de Educação realiza a sua primeira experiência de formação acadêmica inicial em nível de graduação de professores à distância, o Curso de GraduaçãoLicenciatura em Pedagogia da UFRGS, oferecido em nove semestres (3215 h) a docentes em exercício nas escolas públicas.

São 400 professores-alunos que trabalham na rede municipal e estadual de ensino. Estes professores estão divididos em cinco pólos sendo eles: Alvorada, Gravataí, Sapiranga, São Leopoldo e Três Cachoeiras. Cada pólo conta com uma infraestrutura que dispõe de um laboratório com 20 computadores, em média, uma biblioteca com exemplares dos livros adotados nas Interdisciplinas, um espaço para atividades coletivas e espaços para as aulas presenciais - além de material de apoio, como filmadora, máquinas digitais, aparelhos de DVD e projetor multimídia.

O Curso busca superar a dicotomia apresentada pelos modelos convencionais de cursos de formação de professores, que teorizam sobre as transformações nas práticas educativas, sem que essas transformações sejam vivenciadas no próprio ambiente de formação. Para tal, o PEAD elaborou um currículo com características interdisciplinares agregando e articulando os conhecimentos específicos teóricos e práticos em cada semestre, bem como previu o uso de metodologias interativas e o uso intensivo da Internet para desenvolvimento e acompanhamento das aprendizagens.

Somente com uma qualificação fundamentada na reflexão sobre sua própria prática, os professores se sentirão a vontade para usar as tecnologias e criar um novo projeto político - pedagógico (Preti, 2005 p. 10). A intenção é desconstruir os limites rígidos impostos pela concepção física e lógica linear que se tem de escola, da formação e da aprendizagem. Os materiais são desenvolvidos a partir da concepção de Arquiteturas Pedagógicas Abertas ${ }^{\mathrm{i}}$, as quais incentivam a pesquisa e a interação entre os diferentes atores. O deslocamento para o uso intensivo dos materiais interativos na web, em articulação com as outras metamorfoses propostas no curso, viabiliza a construção de conhecimento em comunidades de aprendizagem.

Dentro dessa idéia de reconstrução da formação de professores proposto pelo PEAD, o tutor vem construindo sua identidade. Como um tutor pode orientar os alunos, 


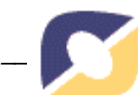

se ele mesmo não vivenciar determinadas experiências? A formação do tutor, nesse contexto, implica no seu preparo para viver a experiência de mudanças na educação que ele irá proporcionar aos alunos. 


\section{A Formação do Tutor no PEAD}

\subsection{Fundamentos}

Na perspectiva de implementação de transformações na formação de tutores, o PEAD propõe metamorfoses que possibilitam, nas usas articulações, a formação do tutor reflexivo. Essas metamorfoses foram descritas em Nevado et al (2007) e caracterizam o deslocamento da concepção de conhecimento enquanto metáfora de "edifício" para a metáfora de "redes".

Essa formação em redes de interação ou comunidades de aprendizagem tem base na interdisciplinaridade e na construção cooperativa do conhecimento, privilegiando uma formação fundamentada na forte interação entre teoria e prática a partir das ações de tutoria.

A organização da formação toma como alicerce o quadro-orientador das ações de tutoria no PEAD, respeitando-se às flexibilizações necessárias às mudanças esperadas no contexto de um curso que se fundamenta numa construção coletiva.

\begin{tabular}{|c|c|c|}
\hline $\begin{array}{l}\text { Acompanha- } \\
\text { mento }\end{array}$ & Tutor do Pólo & Tutor da Sede \\
\hline Função Geral & $\begin{array}{l}\text { *Sua função geral é proporcionar motivação, } \\
\text { feedback, diálogo, orientação personalizada e } \\
\text { orientação coletiva em atividades presenciais e } \\
\text { coletivas, bem como estabelecer vínculos com cada } \\
\text { estudante. Atendendo nos pólos presencialmente. }\end{array}$ & $\begin{array}{l}\text { *Sua função geral é } \\
\text { acompanhar e facilitar o acesso } \\
\text { dos estudantes aos enfoques } \\
\text { temáticos e às atividades } \\
\text { relacionadas nos ambientes. } \\
\text { Atendendo a distância nos } \\
\text { ambientes. }\end{array}$ \\
\hline $\begin{array}{l}\text { Função } \\
\text { Pedagógica }\end{array}$ & $\begin{array}{l}\text { *Analisar sistematicamente o webfólio educacional } \\
\text { com vistas à orientação, bem como manter a equipe } \\
\text { da interdisciplina informada. } \\
\text { *Incentivar a criação e manutenção de comunidades } \\
\text { de interesse on-line entre os estudantes. } \\
\text { *Desenvolver uma pedagogia da pergunta, com } \\
\text { vistas a facilitar que os alunos esclareçam seus } \\
\text { pensamentos e enfrentem suas contradições e } \\
\text { inconsistências. }\end{array}$ & $\begin{array}{l}\text { *Trabalhar a partir da } \\
\text { pedagogia da pergunta - propor } \\
\text { perguntas que ajudem os alunos } \\
\text { a descobrir possíveis contra - } \\
\text { dições ou inconsistências em } \\
\text { suas contribuições nos fóruns e } \\
\text { webfólio educacional. } \\
\text { *Realizar intervenções diretas, } \\
\text { com a anuência da equipe, nas } \\
\text { atividades realizadas e regis - } \\
\text { tradas no webfólio educacional. }\end{array}$ \\
\hline Função social & $\begin{array}{l}\text { *Criar ambiente agradável e acolhedor para a } \\
\text { aprendizagem dos alunos. } \\
\text { *Criar condições para que os alunos estabeleçam } \\
\text { parcerias com outros colegas ao sugerir grupos com } \\
\text { afinidades temáticas. }\end{array}$ & $\begin{array}{l}\text { *Incentivar a troca de } \\
\text { experiências e informações } \\
\text { entre os estudantes. } \\
\text { *Acolher as dúvidas e as } \\
\text { sugestões dos professores- } \\
\text { alunos. }\end{array}$ \\
\hline
\end{tabular}

Quadro 1: Funções do Tutor (elaborado a partir do Guia do Tutor do PEAD) 


\begin{tabular}{|c|c|c|}
\hline $\begin{array}{l}\text { Função } \\
\text { organizativa }\end{array}$ & $\begin{array}{l}\text { *Estabelecer com os alunos agendas de tempos e } \\
\text { realizações. } \\
\text { *Acompanhar as atividades propostas pela equipe do } \\
\text { eixo. } \\
\text { *Informar aos professores todas as questões } \\
\text { Pedagógicas referentes a cada aluno como, por } \\
\text { exemplo, ausências, afastamentos, dificuldades, } \\
\text { alternativas. } \\
\text { *Manter contato com a coordenação do eixo e com a } \\
\text { coordenação geral. }\end{array}$ & $\begin{array}{l}\text { *Dialogar constantemente com a } \\
\text { equipe do eixo e, em especial, } \\
\text { com a equipe da Interdisciplina, } \\
\text { pela qual também é responsável. } \\
\text { *Informar e solicitar ajuda para } \\
\text { questões pedagógicas } \\
\text { específicas da Interdisciplina } \\
\text { *Registrar os casos particulares } \\
\text { de ausências ou dificuldades nas } \\
\text { atividades e no ambiente. }\end{array}$ \\
\hline
\end{tabular}

Quadro 1 (cont.): Funções do Tutor (elaborado a partir do Guia do Tutor do PEAD)

No caso do tutor, o conhecimento sobre os contextos educacionais assume valor especial, pois deverá atuar numa conjuntura que requer a análise fluida, rica e flexível de cada situação, a partir da perspectiva dos tempos, das oportunidades e dos riscos que se imprimem às condições institucionais da educação a distância. Sua formação teórica, disciplinar e pedagógico-didática deverá ser atualizada com a formação na prática dos espaços tutoriais - aspecto que não deveria ser deixado como acaso (Litwin,2001 p. 14).

\subsection{Organização da Formação}

A formação dos tutores é desenvolvida, desde 2006, privilegiando as dimensões teórico-metodológicas e tecnológicas. A partir de 2007, com a criação do Curso de Especialização em Tutoria (ESPEAD), as formações foram sistematizadas e possibilitaram a realização de uma formação continuada, de caráter teórico-prático que contempla a realização de seminários e oficinas de formação, num total de 360 horas.

Entre essas atividades destacamos:

a) oficinas tecnológicas: essas oficinas privilegiam a apropriação tecnológica, porém sem que haja uma dissociação entre a aprendizagem tecnológica e a aprendizagem teórico-metodológica. Para operacionalizar essa articulação, as oficinas ocorrem como apoio as atividades previstas para a apropriação teórico-metodológica. Nessas oficinas forma aprofundados os trabalhos no Rooda, Pbwiki, Breeze e páginas Html. O uso dessa diversidade de ambiente acompanha a opção do curso por oferecer também aos alunos do PEAD uma formação em uso das TICs para implementação do trabalho pedagógico nos laboratórios das escolas.

b) formação específica nas interdisciplinas: antes do início de cada semestre (eixo temático), ocorre uma formação específica em cada uma das interdisciplinas. As Interdisciplinas têm a função de agrupar professores e tutores com papéis e responsabilidades, mas com um objetivo comum. Mesmo os tutores que não atuarão diretamente na tutoria de uma determinada interdisciplina participam da formação. Nessa formação os professores autores apresentam os materiais que serão propostos aos alunos, os quais são experimentados e criticados pelos tutores. A partir disso, os materiais são revistos pelos professores autores, visando a sua adequação. Além disso, mostra-se também imprescindível que o tutor participe dessas discussões sobre os 
materiais e tenha acesso aos mesmos antes do início do trabalho, pois ele só vai poder questionar e interagir com os alunos se conhecer as atividades que estão sendo solicitadas.

c) seminários teórico-metodológicos: esses seminários contemplam estudos e debates interdisciplinares que visam a discussão das arquiteturas pedagógicas utilizadas no Curso, bem como a apropriação de metodologias de interação que permitam ao tutor uma ação reflexiva.

Além da formação oferecida no âmbito do PEAD, a grande maioria dos tutores participa como aluno regular ou como aluno do Programa de Educação Continuada da Pós-Graduação (PEC) dos seminários SA tutoria em EAD. Os seminários são voltados para o trabalho de tutoria, nas quais os tutores realizam uma complementação dos estudos teóricos e metodológicos.

\subsection{Uso dos espaços virtuais}

Ambientes virtuais (AVAs) são espaços nos quais professores, alunos e tutores compartilham as tecnologias de informação e comunicação de uma forma mais dinâmica. Ainda que do ponto de vista tecnológico os AVAs sejam definidos como conjuntos organizados de recursos, funcionalidades ou ferramentas multimídias, do ponto de vista sócio-cognitivo os AVAs são definidos como "espaços ou comunidades organizadas com o propósito de aprender", o que implica na presença e articulação de (i) uma concepção definida sobre conhecimento e aprendizagem; (ii) uma proposta metodológica coerente que concretize essa concepção em propostas de ações e interações (iii) um suporte tecnológico potente para apoiar e incrementar as atividades e trocas grupais.

A educação na virtualidade, do mesmo modo que na presencial idade, pode ocorrer sob distintas orientações educativas. Ambientes concebidos para desenvolver propostas de ensino - ambientes para ensinar buscarão simular a organização da escola tradicional. Ambientes concebidos para mediação da aprendizagem darão suporte às interações e produções individuais e coletivas.

\section{Dentro da perspectiva de formação proposta pelo PEAD, como são utilizados os espaços virtuais?}

O ROODA é o principal ambiente virtual do curso (figura1) onde destacamos as seguintes ferramentas:

Diário de Bordo: o diário de bordo é usado como espaço de meta-reflexão, no qual os tutores registram suas aprendizagens, dificuldades, angústias, conquistas, enfim, todo o trabalho desenvolvido e que consideram importante compartilhar com os colegas. Esse material posteriormente é lido e comentado pelos tutores e professores.

Fórum e Sala de bate-papo: esses espaços são utilizados para discussões teóricometodológicas, bem como para interação e organização do trabalho. Os tutores usam também o Msn e o Skipe para uma comunicação em tempo real.

Webfólio: constituem-se em "espaços" privilegiados onde os tutores registram os processos e produtos da aprendizagem num determinado contexto. Os webfólios reúnem 
elementos que permitem o acompanhamento e avaliação continuada dos processos e servem para orientar as intervenções docentes durante o desenvolvimento da formação.

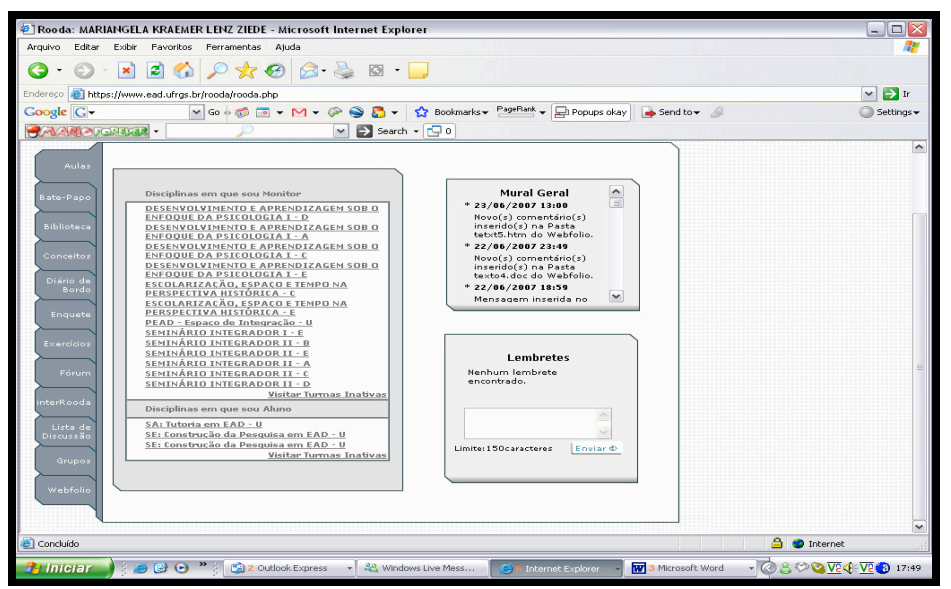

Figura1 - Ambiente ROODA

Fonte: http://www.ead.ufrgs.br/rooda. Acesso em 10/05/2008

Pbwiki e o blog: são utilizados para publicações e trocas de informação entre tutores. Os blogs e pbwikis são páginas simples, com facilidade de criação e publicação, não sendo necessário nenhum conhecimento de programação para criá-los e atualizá-los. Além disso, publicam idéias em tempo real e possibilitam a interação com qualquer pessoa do mundo que esteja conectada, além de ajudar a construir redes sociais e redes de saberes.

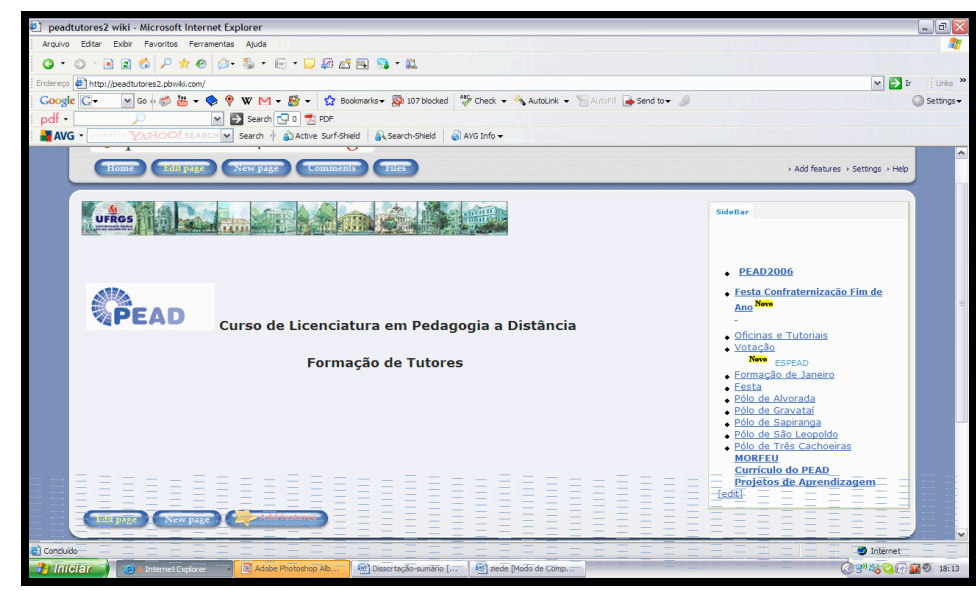

Figura 2 -Ambiente Pbwiki

Fonte: http://peadtutores.pbwiki.com.Acesso em 15/05/2008

O Wiki permite que os documentos sejam editados coletivamente com muita facilidade, por meio da utilização de um navegador web. Ele pode ser acessado pelo endereço $<$ http://peadtutores.pbwiki.com>.As publicações podem ser adicionadas por vários usuários e atualizadas a todo momento, trabalhando com hipertexto ao invés do texto 
seqüencial. Desse modo, é possível complementar idéias e inserir novas informações; o resultado dessa partilha é o conteúdo de um wiki se atualizar graças à coletividade.

Os blogs são também usados para experienciar algumas das atividades que os alunos realizam posteriormente. A partir de 2007, com o inicio do ESPEAD o blog é também utilizado para construir o "Portfólio de Aprendizagem" no qual os tutores realizam reflexões sobre suas aprendizagens, bem como apresentação evidência que apoiem as suas argumentações. A construção dos "Portfólios de Aprendizagem" subsidia a avaliação dos tutores.

\section{Avaliação das Atividades dos Tutores}

Nesse artigo, concebemos a aprendizagem como um processo contínuo, - mas não linear caracterizado por desequilíbrios e reequilibrações, - de produção do novo, pelo menos do ponto de vista do sujeito. A aprendizagem tem como fonte a ação do sujeito sobre o mundo (físico, social, simbólico), bem como a reflexão sobre a sua ação, permitindo que sujeito compreenda o mundo e compreenda-se a si mesmo (metacognição), numa construção dialética.

Como consequiência dessa perspectiva de aprendizagem, o sentido da avaliação não poderá ser mais o de uma avaliação centrada na retenção da informação e no desempenho. A concepção de aprendizagem enquanto um processo de construção de novas formas de pensar e agir, de invenção e criação, desloca o foco da avaliação:

(i) das performances e produtos para as construções de novos instrumentos cognitivos;

(ii) das observações e "julgamentos" externos, que comparam o sujeito a algum ideal que ele deva alcançar para as análises e auto-análises do novo que está em produção nas situações de interação;

(iii) da avaliação "da" aprendizagem para a avaliação "na" aprendizagem, conforme propõe Maraschin (2000).

São realizadas, regularmente, avaliações do trabalho de tutoria, dentro de uma metodologia cooperativa de avaliação. Belloni (1995) esclarece que "a avaliação é um processo de tomada de consciência e de aferição da propriedade do desenvolvimento de uma ação, cujo objetivo é a correção e aperfeiçoamento do rumo e não simplesmente a punição". Nesta avaliação os tutores da sede e dos pólos elegeram categorias e indicadores para a montagem do instrumento de avaliação por pares, com igual valoração para a auto-avaliação, a avaliação dos pares e a avaliação dos docentes.

A avaliação teve início com a realização das auto-avaliações e prosseguiu com a avaliação dos pares (dois colegas tutores) e finalmente com a avaliação dos docentes responsáveis pelas interdisciplinas que atuaram na orientação dos tutores. Os (poucos) casos de "conflito" entre as avaliações abriram debates que se mostraram produtivos no sentido da construção de convergências e reformulações nas formas de conceber a avaliação.A seguir apresentamos um quadro com as categorias e indicadores utilizados:

\begin{tabular}{l|l} 
Categorias & Indicadores
\end{tabular}




\begin{tabular}{|c|l|}
\hline $\begin{array}{c}\text { Prática das } \\
\text { concepções e } \\
\text { metodologias do } \\
\text { PEAD }\end{array}$ & $\begin{array}{c}\text { Promoção da construção de uma comunidade de } \\
\text { aprendizagem; } \\
\text { - Valorização das experiências dos alunos e os saberes } \\
\text { constituídos na prática; }\end{array}$ \\
& $\begin{array}{l}\text { - Análise crítica de produções apresentadas no ambiente virtual; } \\
\text { - Uso de procedimentos baseados na metodologia do curso para } \\
\text { orientar o feedback aos alunos; } \\
\text { - Promover o desequilíbrio das certezas; } \\
\text { - Conhecimento e Reflexão sobre conceitos/conteúdos; }\end{array}$ \\
\hline & Evidências e fontes (para cada indicador): \\
\cline { 2 - 3 } & Avaliação com respeito à categoria: \\
\hline
\end{tabular}

Quadro 2: Categorias e indicadores para avaliação de tutores do PEAD

Fonte: Avaliação dos tutores $2006<$ http://avaliacao.pbwiki.com>

\begin{tabular}{|c|c|}
\hline \multirow[t]{3}{*}{$\begin{array}{l}\text { Atendimento aus } \\
\text { alunos }\end{array}$} & $\begin{array}{l}\text { - Comentários nos webfólios; } \\
\text { - Comentários nos blogs; }\end{array}$ \\
\hline & Evidências e fontes (para cada indicador): \\
\hline & Avaliação com respeito à categoria: \\
\hline \multirow[t]{3}{*}{$\begin{array}{l}\text { Interações com } \\
\text { professores e } \\
\text { tutores }\end{array}$} & $\begin{array}{l}\text { - Provimento de informações sobre as atividades dos alunos; } \\
\text { - Participação nas reuniões da interdisciplina, da tutoria etc. } \\
\text { - Trocas com tutores da sede usando as facilidades de } \\
\text { comunicação (fórum, Chat; mensagem instantânea etc.); } \\
\text { - Trocas com tutores de Pólo usando as facilidades de } \\
\text { comunicação (fórum, Chat; mensagem instantânea etc.); } \\
\text { - Busca e oferta de novas informações sobre o curso; } \\
\text { - Colaboração na solução de problemas no curso; } \\
\text { - Propostas de discussão no ambiente; }\end{array}$ \\
\hline & Evidências e fontes (para cada indicador): \\
\hline & Avaliação com respeito à categoria: \\
\hline $\begin{array}{l}\text { Fluência na } \\
\text { telemática }\end{array}$ & $\begin{array}{l}\text { - Ambiente Rooda; } \\
\text { - Pbwiki; } \\
\text { - Blog; } \\
\text { - Provedores de serviço tais como: bubbleshare, you tube etc. } \\
\text { - Editor de texto; } \\
\text { - Editor de apresentação; } \\
\text { - Editor de imagens; } \\
\text { - Editor de página; }\end{array}$ \\
\hline
\end{tabular}




\begin{tabular}{|l|l|}
\multirow{2}{*}{} & Evidências e fontes (para cada indicador): \\
\cline { 2 - 3 } & Avaliação com respeito à categoria: \\
\hline Atitude & - Comportamento ético; \\
Profissional & - Autonomia, Iniciativa; \\
& - Disposição para cooperar/colaborar; \\
& - Engajamento com os propósitos do curso. \\
\hline
\end{tabular}

Quadro 2 (cont.): Categorias e indicadores para avaliação de tutores do PEAD

Fonte: Avaliação dos tutores $2006<$ http://avaliacao.pbwiki.com>

A título de ilustração apresentamos alguns extratos envolvendo auto-avaliações de tutores, avaliações dos pares e avaliações de docentes responsáveis pelas interdisciplinas:

\section{Categoria: Engajamento como os propósitos do curso:}

Extrato 1: Auto-avaliação - (...) O trabalho desenvolvido neste semestre pelo nosso grupo foi de muita colaboração e articulações, sempre em contato com os tutores de pólo e com as minhas colegas prof ${ }^{\mathrm{a}} \mathrm{B}$ e a tutora $\mathrm{B}$ e principalmente com a $\operatorname{prof}^{\mathrm{a}} \mathrm{C}$. Em síntese diria que o nosso trabalho foi igual a construção de uma casa, pois fomos de semana em semana construindo esta caminhada, sempre levando em consideração os indicativos trazidos pelos alunos. Gostaria de ressaltar a metodologia utilizada pelo grupo que foi fundamental para a realização do trabalho. Onde ação - reflexão esteve sempre presente (Tutora C).

Extrato 2: Avaliação de colega tutor (...) A tutora demonstrou atitudes éticas e colaborativas ao desempenhar seu trabalho. Sua análise evidencia a metodologia de seu grupo em busca da ação-reflexão para o desenvolvimento de seu trabalho junto às alunas. Da mesma forma, parece-me que a tutora utilizou a mesma lógica para o seu crescimento profissional na função que desempenhou no semestre passado (Tutora D).

Extrato 3: Avaliação do docente Um dos aspectos que os alunos de cursos a distância baseados na web valorizam é a forma como são acompanhados, ouvidos, e atendidos em suas demandas. Não é suficiente dar um retorno, pois importa muito também a fato dos alunos se sentirem parte de um projeto de aprendizagem, no qual participam de forma cooperativa e colaborativa. A forma como esse processo se desenvolve conta muito, e esse é um aspecto no qual a ação da Tutora $\mathrm{C}$ se sobressai, atuando com competência, seja através das interlocuções nas diversas ferramentas, como blogs, webfólios, diários de bordo dos alunos, fóruns, bate-papo e correio eletrônico, sempre no momento oportuno (Docente G).

\section{Categoria: Atitude Profissional}

Extrato1: Auto-avaliação (...). Gostaria de ressaltar a metodologia de trabalho adotada pelo nosso grupo de trabalho que no meu entender foi bastante diferenciada e 
que nos permitiu ter um olhar atento para cada uma das atividades que foram propostas e também como as alunas reagiam diante das mesmas. O nosso grupo (eu, a tutora $\mathrm{B}$ e a prof $^{a}$ D) nos reuníamos uma vez por semana para pensar/discutir como iríamos avaliar a atividade da semana, saber o andamento de cada de aluna, sempre estamos nos articulando (Tutora E).

Extrato2: Avaliação de colega tutor (...). A tutora evidenciou, ao longo dos indicadores, o envolvimento com as concepções e práticas do PEAD. Seu grupo conseguiu organizar uma lógica de acompanhamento das alunas muito interessante. A tutora demonstrou que realiza intervenções críticas nas produções das alunas, de forma a propor uma reflexão sobre a sua aprendizagem, sem deixar de valorizar as concepções e experiências das mesmas A tutora fez seu papel, incentivando, auxiliando, desafiando os alunos, buscando solucionar problemas (Tutora F).

A partir desse processo de avaliação cooperativa foi possível identificar um gradual processo de apropriação da proposta pedagógica do PEAD, bem como observar algumas necessidades de aprofundamento de estudos teóricos, destacando-se o uso da metodologia problematizadora e a intensificação dos debates sobre a aprendizagem na perspectiva construtivista. A partir desse processo de avaliação cooperativa foi possível identificar um gradual processo de apropriação da proposta pedagógica do PEAD, bem como observar algumas necessidades de ajustes na formação. As principais reconstruções introduzidas na formação focalizaram: (1) o aprofundamento de estudos, destacando-se o uso da metodologia problematizadora, mediante atividades de análise de casos; (2) a proposta de uma nova arquitetura pedagógica baseada na construção conceitual cooperativa como suporte a discussão/apropriação de conceitos fundamentais da concepção construtivista e (3) a utilização de técnicas de grupo visando à resolução de problemas enfrentados na atividade de tutoria.

Adicionalmente, a avaliação colaborativa ocasionou uma grande circulação de informações sobre os trabalhos realizados pelos tutores, além de proporcionar aprendizagens sobre o próprio processo de avaliação, já que implicou em análises das auto-avaliações e evidências de aprendizagens apresentadas pelos seus pares.

A avaliação colaborativa apresentou como resultado adicional uma grande circulação de informações sobre os trabalhos realizados pelos tutores, além de proporcionar aprendizagens sobre o próprio processo de avaliação, já que implicou em análises das auto-avaliações e evidências de aprendizagens apresentadas pelos seus pares.

\section{Considerações Finais}

No Curso, além de realizar leituras ou participar dos encontros de formação, o tutor busca um constante re-pensar e re-fazer da atividade de tutoria por meio da atitude de pesquisar.

Considerando que o Curso está em desenvolvimento, tendo uma duração de nove semestres, será possível seguir acompanhando e avaliando o processo de formação dos tutores. Os próximos passos apontam para uma etapa de consolidação da comunidade de aprendizagem, mediante a intensificação das interações a distância e do uso de arquiteturas pedagógicas de construção cooperativa. 
Nesses quatro primeiros semestres do PEAD, tivemos resistências e conquistas por parte de todos os sujeitos envolvidos. Alguns pensavam ser impossível aliar educação e informática a sua prática, mas as múltiplas interações realizadas nos AVAs já criaram redes de cooperação entre os professores-alunos dos pólos, professores e tutores, fomentando a formação e a manutenção de comunidades de aprendizagem. Evidencia-se, portanto, uma experiência significativa de formação continuada de todos os sujeitos envolvidos no processo pedagógico, na perspectiva de uma busca permanente de qualificação.

\section{Referências Bibliográficas}

CARVALHO, M. J. S., NEVADO, R. A. d. e BORDAS, M. C. (2006b). Licenciatura em Pedagogia a Distância: Anos Iniciais do Ensino Fundamental - Guia do Tutor. Porto Alegre: PEAD/UFRGS.

LITWIN, E. (Org.) (2001) Educação a distância, temas para o debate de uma nova agenda educativa. São Paulo: Artmed,

MARASCHIN, C. Avaliação (da ou na) Aprendizagem In: Anais do II Congresso Internacional de Educação do Colégio Coração de Jesus. Florianópolis, 2000.

PETERS, Otto (2004). A educação a distância em transição: tendências e desafios. Trad. Mendes, Ferreira de Souza, Leila São Leopoldo, RS ed.UNISINOS

PRETI, Oreste (org.). Educação a Distância: inícios e indícios de um percurso. NEAD/IE - UFMT. Cuiabá: UFMT, 1996.

NEVADO, R. A. (Org.); CARVALHO, Marie Jane Soares (Org.); MENEZES, Crediné Silva de (Org.) (2007). Aprendizagem em rede na educação a distância: estudos e recursos para a formação de professores. 1. Ed. Porto Alegre: RICARDO LENZ EDITOR. V. 1. 224 p.

NEVADO, R. A., C. S. Menezes, Carvalho, M. J. S. (2006) Educação a distância mediada pela Internet: uma abordagem interdisciplinar na formação docente. RENOTE, v.4, n.2

NEVADO, R. A.; CARVALHO, Marie Jane Soares; MENEZES, Crediné Silva de. Categorias e indicadores para avaliação de tutores do PEAD: Avaliação dos tutores 2006. Disponível em < http://avaliacao.pbwiki.com> (Acesso restrito). Acesso em: 15 de março de 2008.

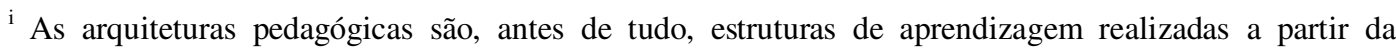
confluência de diferentes componentes: abordagem pedagógica, software, internet, inteligência artificial, educação a distância, concepção de tempo e espaço (Carvalho, Nevado, e Menezes, 2005). Seus pressupostos curriculares compreendem pedagogias abertas capazes de acolher didáticas flexíveis, maleáveis, adaptáveis a diferentes enfoques temáticos.
} 